\title{
Non-destructive Estimation of Water Status of Sugarcane Leaf Using Spectral Reflectance Measurement
}

\author{
Kenjiro MAEDA ${ }^{*}$, Masami UENO ${ }^{* *}$ and Yoshinobu KAWAMITSU** \\ "The United Graduate School of Agricultural Science, University of the Ryukyus, \\ Nishihara, Okinawa, 903-0129 Japan \\ "Faculty of Agriculture, University of the Ryukyus, Nishihara, Okinawa, 903-0129 Japan
}

\begin{abstract}
Non-destructive estimation of relative water content (RWC) of sugarcane leaf was useful in understanding precise irrigation for saving limited water resources. Visible and near-infrared reflectance spectra were measured using a spectroradiometer to clarify the response of reflectance properties, as a basic study on the application of remote sensing. Reflectance spectrum and RWC were measured continuously with a constant interval under natural dryness conditions from $95 \%$ to $5 \%$. Reflectance spectra increased with the reduction of RWC. Changes in reflectance were small until $25 \%$ of RWC, and then became large within the range from $25 \%$ to $15 \%$. Reduction of chlorophyll content in the samples with the decrease of RWC seemed to be a cause of rapid increase of reflectance. Red edge position (REP) was shifted to the short wavelength side with the reduction of RWC. Some reflectance indices near $700 \mathrm{~nm}$ showed high correlation with RWC in each sample. A well-fitted regression model for all samples from different plants was not found out using $700 \mathrm{~nm}$ reflectance. Difference of the reflectance at short wavelength and the long one showed comparatively good correlation to all samples. At a plant level, RWC can be predicted non-destructively with a sufficient accuracy using the developed model.
\end{abstract}

Key words: Leaf water content, Non-destructive estimation, Spectral reflectance, Sugarcane

\section{Introduction}

Sugarcane is grown at Nansei Arcs mainly Okinawa islands, in Japan, which is a main crop in this area. This area is located in a subtropical zone with high temperature and humidity. Severe drought sometimes takes place in the summer season due to uneven distribution of rainfall, though the total annual volume exceeds $2000 \mathrm{~mm}$. Shortage of water brings a remarkable yield reduction of sugarcane. The water source and irrigation facilities such as underground dams, sprinkler irrigation and drip irrigation have been constructed in order to overcome this situation. The irrigated area of the farmland has been gradually increased.

However, water has to be used more efficiently because the water resources of the islands are severely limited due to the lack of big rivers or ponds as water sources. It is necessary for saving water to evaluate precisely the amount of water demand for irrigation. Water stress conditions in plants depend on many factors, which are usually different in every sugarcane field. Strictly speaking, water status, and the water demand should be estimate, not only for a single field, but also for all fields in the irrigated area. A key point of the system is to grasp exact information about the water stress conditions of sugarcane. Usually, it is quite difficult to do this because the target area is so wide. Remote sensing is expected to be a powerful tool for detecting the water status of plant and soil. There are some reports to apply the remote sensing technique for the optimum irrigation (Bandara, 2003; Martin et al, 2003). Although the technique is effective in the rough estimation of water demand, it is not enough for a precise estimation on small islands. Lack of basic studies on the characteristics of light reflectance of sugarcane leaves prevents effective application. Therefore, visible and near-infrared reflectance spectra of sugarcane leaves were measured using a spectroradiometer to clarify the response of reflectance to the water stress status in this study.

\section{Material and Methods}

The sugarcane material used for the experiments was Saccharum spp. cv. NiF8. The materials were obtained from sugarcane grown in pots $(1 / 2000 \mathrm{a}$ Wagner pot) in a greenhouse at the University.

The topmost fully expanded leaves were sampled in water in early morning. Test pieces of $25.5 \mathrm{~mm}^{2}$ area were cut from the leaves with a razor blade. These were used to measure the initial leaf relative water content $\left(\mathrm{RWC}_{\mathrm{int}}\right)$, spectral reflectance and chlorophyll content. RWC was determined after Barr and Weatherley (1962). The initial fresh weight $\left(\mathrm{FW}_{0}\right)$ of a test piece was measured using an analytical balance immediately after a treatment. The test piece was hydrated in a vial filled with distilled water until to full turgidity for 4 hours under the

Accepted on January 12, 2005 
ordinary room light and temperature. After hydration, the test piece was taken out of the vial with tweezers and its surface moisture of it was removed quickly with tissue paper. The fully turgid weight (TW) was then immediately measured. The test piece was dried in an oven at $90^{\circ} \mathrm{C}$ for $1 \mathrm{hr}$, and then the dry weight (DW) was measured. The initial leaf relative water content was defined as follows.

$$
\mathrm{RWC}_{\text {int }}=\left[\left(\mathrm{FW}_{0}-\mathrm{DW}\right) /(\mathrm{TW}-\mathrm{DW})\right] * 100
$$

Reflectance spectra were obtained using a spectroradiometer (FieldSpec Handheld, Analytical Spectral Devices) equipped with a bifurcated fiber probe and an artificial light source (halogen lamp, $2 \mathrm{~W}$ ) (Fig.1). The sampling interval of the reflectance was $1.6 \mathrm{~nm}$ in the scanning range of $400-1000 \mathrm{~nm}$. The specimen was placed between two black colored plates with narrow space between, and then put on an electric balance in order to measure the weight. The fiber probe was attached onto the upper plate through a small whole. The clearance between the test piece and the top of prove was kept at $1 \mathrm{~mm}$. The test piece was shaded from outside light. A reflectance spectra series was obtained continuously with a constant interval.

The fresh weight of the test piece (FW) decreased gradually in a natural dryness condition. FW was measured simultaneously with each spectral scanning. After the series of measurements, dry weight (DW) was measured. RWC at each measurement of spectral reflectance was defined as follows.

$$
\mathrm{RWC}=\mathrm{RWC}_{\text {int }} *\left[(\mathrm{FW}-\mathrm{DW}) /\left(\mathrm{FW}_{0}-\mathrm{DW}\right)\right]
$$

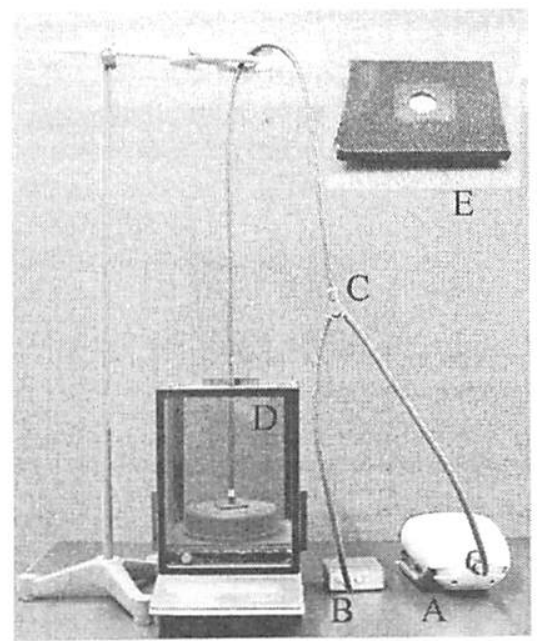

Fig.1. Test apparatus for measuring spectral reflectance and weight of leaves.
A: Spectroradiometer B: Light source
C: Fiber probe D: Electric balance
E: Black colored plates

Chlorophyll content was determined after Wintermans and De Mots (1965) by measuring the values of absorbance at 665,649 and $750 \mathrm{~nm}$ in $96 \%$ $(\mathrm{v} / \mathrm{v})$ ethanol. The values of chlorophyll content $(\mu \mathrm{g} / \mathrm{ml})$ were calculated by the following formula:

$$
\begin{aligned}
& \mathrm{Chl}_{\mathrm{a}}=13.70\left(A_{665}-A_{750}\right)-5.76\left(A_{649}-A_{750}\right) \\
& \mathrm{Chl}_{\mathrm{b}}=25.80\left(A_{649}-A_{750}\right)-7.60\left(A_{665}-A_{750}\right) \\
& \mathrm{Chl}_{\mathrm{a}+\mathrm{b}}=6.10\left(A_{665}-A_{750}\right)+20.04\left(A_{649}-A_{750}\right)
\end{aligned}
$$

where, $A$ meant the absorbance and the subscript was wavelength $(\mathrm{nm})$. $\mathrm{Chl}_{\mathrm{a}}, \mathrm{Chl}_{\mathrm{b}}$ and $\mathrm{Chl}_{\mathrm{a}+\mathrm{b}}$ were the contents of chlorophyll a, chlorophyll b and their respective sums.

\section{Results and Discussion}

\subsection{Change in reflectance spectra with RWC}

Values of the reflectance at any wavelength increased gradually with decreasing the RWC of the test piece, as shown in Fig.2. Figure 3 showed a trend in which the increase was small except in the initial drying stage from $95 \%$ to $85 \%$. A remarkable change was observed within the RWC range from $25 \%$ to $15 \%$.

The "red edge" was generally defined as a steep rise in the reflectance spectra from $680 \mathrm{~nm}$ to $750 \mathrm{~nm}$. An inflection point in the red edge was called the 'red

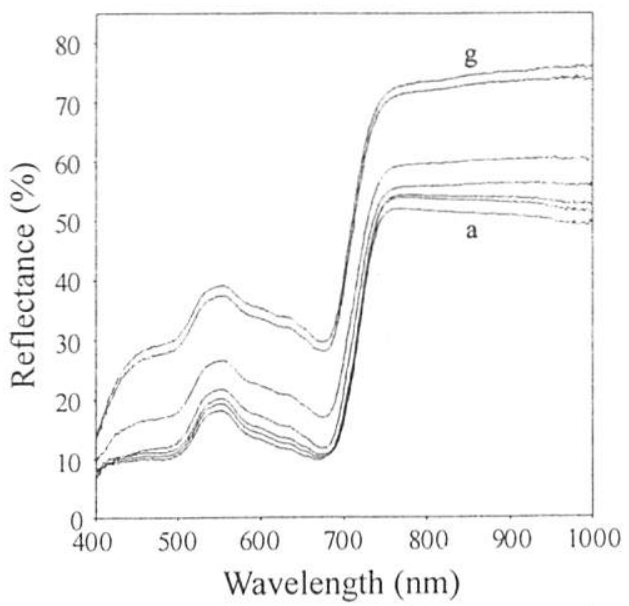

Fig.2. Spectral reflectance of sugarcane leaves with several relative water content (RWC). RWC; a: $94.5 \%$, b: $90.0 \%$, c: $85.0 \%$, d: $25.0 \%$, e: $20.0 \%, \mathrm{f}: 14.9 \%, \mathrm{~g}: 4.8 \%$

edge position', denoted as REP. REP could be obtained from a peak of the first derivatives of the reflectance spectrum. The first derivatives were calculated as follows:

$$
\Delta R\left(\lambda_{i}\right)=\frac{\left(\sum_{j=1-2}^{i+4} R\left(\lambda_{j}\right)-\sum_{j=i-4}^{i+2} R\left(\lambda_{j}\right)\right) / 7}{\Delta \lambda}
$$

where, $R(\lambda)$ was the reflectance at $\lambda \mathrm{nm}, \Delta R(\lambda)$ was the approximate derivative at $\lambda \mathrm{nm}$. $i$ was a consecutive number relating to the wavelength. $\Delta \lambda$ was set $3.2 \mathrm{~nm}$ in this calculation. 
The wavelength at REP shifted to the short side along with the reduction of RWC. Until $20 \%$ of RWC, the REP shift was at least $3 \mathrm{~nm}$ as shown in Fig.3. While RWC decreased from $20 \%$ to $15 \%$, REP moved more than $14 \mathrm{~nm}$. This corresponded to the jump of the reflectance.

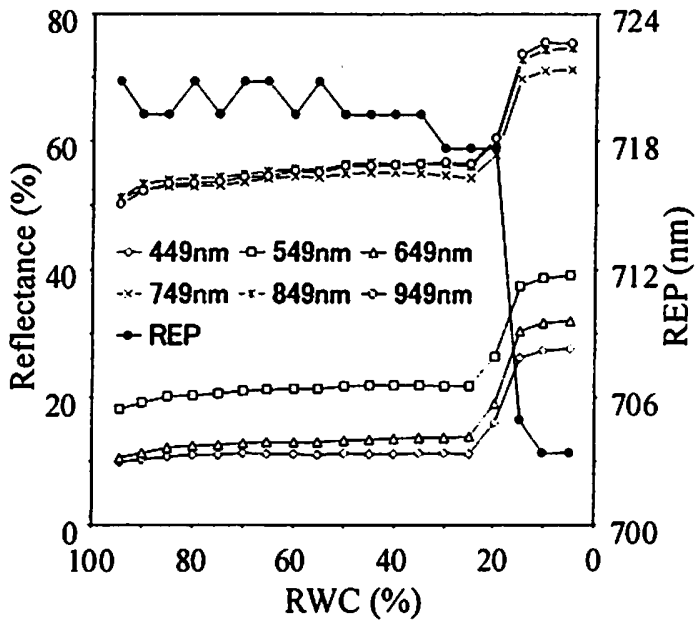

Fig.3. Changes in leaf reflectance at $449 \mathrm{~nm}$, $549 \mathrm{~nm}, 649 \mathrm{~nm}, 749 \mathrm{~nm}, 849 \mathrm{~nm}$ and $949 \mathrm{~nm}$, and red edge position (REP) with the decreasing of the relative water content (RWC).

\subsection{Change in chlorophyll content}

In this study, it was not clarified what caused the remarkable changes in the reflectance spectrum and REP in the low range of RWC. It was supposed that bulliform cells existed in the adaxial surface of the leaf shrunk with decreasing the leaf water content. In other wards, internal and/or external change of the leaf structure seemed to be a cause of the remarkable change in the reflectance characteristics. Moreover, it was thought that the reduction of chlorophyll content as shown in Fig.4 was also one of the factors. More investigation is necessary to clarify these phenomena.

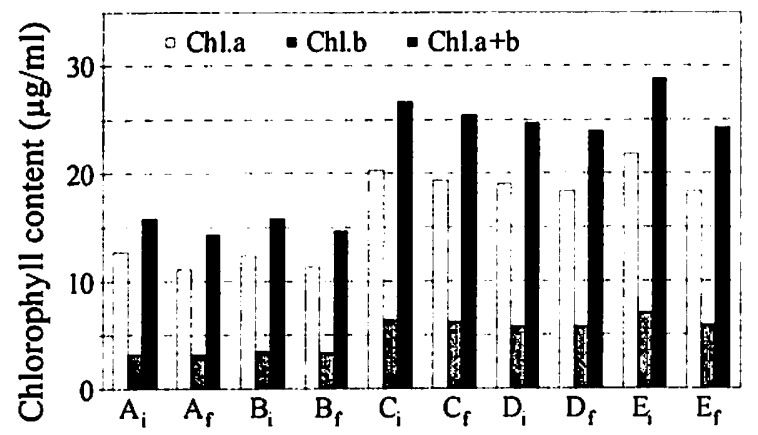

Fig.4. The chlorophyll content at the initial state and the final state for five samples (A to $E$ )

Subscript i: initial state, f: final state

\subsection{Sensitivity of reflectance and spectral indices}

Sensitivity (Carter, 1991) was calculated in order to select effective wavelengths for the estimation of leaf RWC. The sensitivity at a wavelength was defined as a ratio of the reflectance at a current RWC to that at the $R W C_{\text {int }}\left(=R W C / R W C_{\text {int }}\right)$. Its values were plotted to the wavelength as shown in Fig.5. Two small peaks were observed at $560-660 \mathrm{~nm}$ and near $700 \mathrm{~nm}$ in the sensitivity-wavelength relation, when RWC was more than $25 \%$. Remarkable change occurred at $430-520 \mathrm{~nm}$ and at $580-700 \mathrm{~nm}$ when RWC was less than $25 \%$. Peaks such as that near $700 \mathrm{~nm}$ showed distinctive features in the RWC. Therefore, the spectral indices were calculated using the ratio and difference at specific points. Correlations between these indices and the RWC were investigated. The range of RWC was limited to more than $25 \%$ from the point of view of practical irrigation and water management.

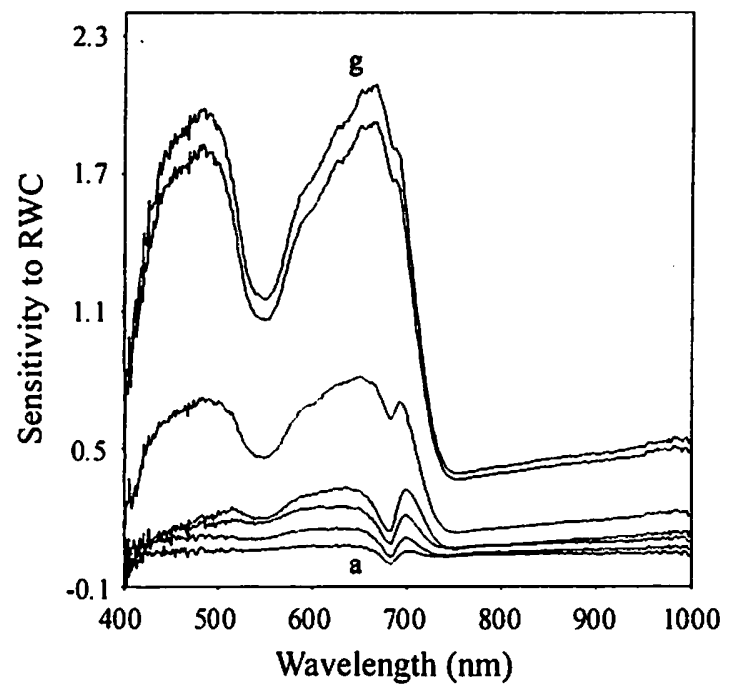

Fig.5. Reflectance sensitivity vs. wavelength with relative water content (RWC).

RWC; a: $90.0 \%$, b: $85.0 \%$, c: $60.0 \%$, d: $25.0 \%$, e: $20.0 \%$, f: $14.9 \%$, g: $4.8 \%$

\subsection{Prediction of RWC using reflectance indices}

The indices listed in Table 1 showed high correlations above 0.9 in all cases of each test piece, as shown Fig.6A. However, the agreement of these regression equations decreased, largely by applying to all test pieces especially in the index $R(709.7)$. The reflectance indices such as $R(532.0) / R(700.2)$ and $R(408.2) / R(495.5)$ showed comparatively good correlation to all samples. $R(519.3)-R(700.2)$ and $R(846.2)-R(962.0)$ also showed good correlation.

Figure $6 \mathrm{~B}$ showed the distribution of index $R(846.2)-R(962.0)$ to RWC. It seemed to be difficult to predict the precise RWC to all samples from different. In order to check the applicability to different leaves in the same plant, the following model was evaluated using two test pieces

$$
\mathrm{RWC}(\%)=34.249[R(519.3)-R(700.2)]+185.44
$$

One of the test pieces was used for making a 
calibration equation, and the other was for evaluating the accuracy of the estimation. The Correlation coefficient of the evaluation sample was very high (0.99), as shown in Fig. 6C, and the standard error of evaluation (SEE, 2.73\%) was smaller than of the calibration (SEC, 3.23\%). Thus, RWC could be estimated or measured with a sufficient accuracy using reflectance indices at least at leaf level. The cause of the differences in the reflectance properties of different plants should be clarified. Further, a RWC estimating model applicable to any leaf should be developed.

Table.1. Spectral indices closely correlated to relative water content (RWC) of sugarcane leaves.

\begin{tabular}{|c|c|c|c|c|c|c|}
\hline \multirow[t]{2}{*}{ Reflective indices } & \multicolumn{6}{|c|}{$\begin{array}{c}\text { Correlation Coefficients } \\
\text { (Standard Error) }\end{array}$} \\
\hline & A & $\mathrm{B}$ & $\mathrm{C}$ & D & $E$ & All \\
\hline \multirow[t]{2}{*}{$R(709.7)$} & -0.95 & -0.90 & -0.97 & -0.98 & -0.99 & -0.21 \\
\hline & $(6.18)$ & $(9.70)$ & $(5.32)$ & $(3.86)$ & $(2.52)$ & $(19.88)$ \\
\hline \multirow[t]{2}{*}{$R(532.0) / R(700.2)$} & 0.99 & 0.99 & 0.98 & 0.99 & 0.97 & 0.79 \\
\hline & $(3.06)$ & $(3.58)$ & $(4.09)$ & $(3.24)$ & $(5.05)$ & $(12.58)$ \\
\hline \multirow[t]{2}{*}{$R(519.3)-R(700.2)$} & 0.98 & 0.99 & 0.98 & 0.99 & 0.99 & 0.46 \\
\hline & (4.17) & $(2.97)$ & $(4.01)$ & $(2.72)$ & $(3.23)$ & (18.08) \\
\hline \multirow[t]{2}{*}{$R(408.2) / R(495.5)$} & 0.90 & 0.93 & 0.87 & 0.93 & 0.87 & 0.88 \\
\hline & $(8.31)$ & $(8.30)$ & $(10.15)$ & $(7.36)$ & $(10.00)$ & $(9.75)$ \\
\hline \multirow[t]{2}{*}{$R(846.2)-R(962.0)$} & 0.88 & 0.92 & 0.90 & 0.94 & 0.94 & 0.89 \\
\hline & $(9.33)$ & $(8.79)$ & $(8.82)$ & $(7.00)$ & $(6.95)$ & $(9.19)$ \\
\hline
\end{tabular}
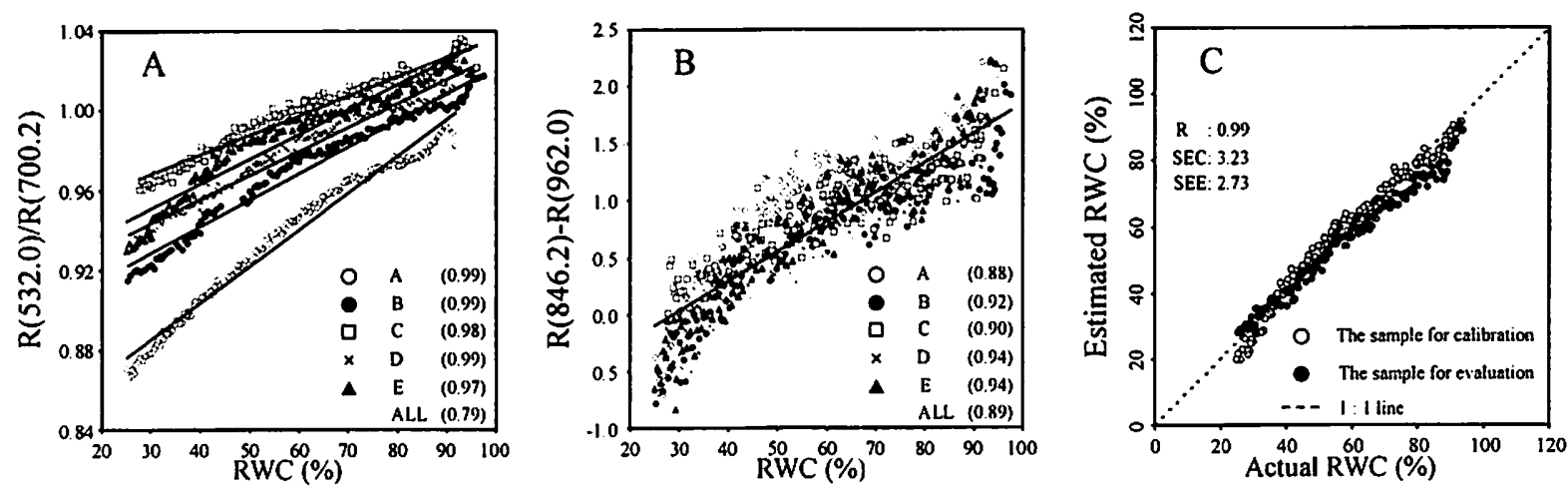

Fig.6. Relationship between RWC and reflective indices (A, B) and Relationship between measured and estimated RWC (C)

\section{Conclusions}

A) Reflectance spectra increased with the reduction of RWC of sugarcane leaves. The change was small until to $25 \%$, and then it turned large from $25 \%$ to $15 \%$ of RWC.

B) REP shifted to the short wavelength side with the rapid increase of reflectance.

C) The indices by the reflectance near $700 \mathrm{~nm}$ showed high correlation with RWC to each sample. In addition, $R(846.2)-R(962.0)$ showed comparatively good correlation with all samples.

D) RWC of the same plant can be predicted non-destructively with sufficient accuracy using the developed model.

\section{Acknowledgement}

The authors thank toe authority of Japan Society for the Promotion of Science (JSPS) for financial support in doing this work.

\section{References}

Bandara, K.M.P.S., 2003: Monitoring irrigation performance in Sri Lanka with high-frequency satellite measurements. Agric. Water Manage., $\mathbf{5 8}(2), 159-170$

Barr, H.D. and Weatherley, P.E., 1962: A re-examination of the relative turgidity technique for estimating water deficit in leaves. Aust. J. Biol. Sci., 15, 413-428

Carter, G.A., 1991: Primary and secondary effect of water content on the spectral reflectance of leaves. American J. Botany, 78(7), 916-924

Martin de Santa Olalla, F., Calera, A., and Dominguez, A. 2003: Monitoring irrigation water use by combining Irrigation Advisory Service, and remotely sensed data with a geographic information system. Agric. Water Manage., 61(2), $111-124$

Wintermans, I.F.G.M. and De Mots, A., 1965: Spectrophotometric characteristics of chlorophylls $\mathrm{a}$ and $\mathrm{b}$ and their pheophytins in ethanol. Biochem. Biophys. Acta, 109, 448-453 